\title{
Perdas de nitrogênio por volatilização de amônia com aplicação de uréia em solo de várzea com diferentes níveis de umidade
}

\author{
Nitrogen loss by ammonia volatilization with urea application in wetland soil with different soil water status
}

\author{
Francisco Mendoza Duarte ${ }^{\mathrm{I}}$ Elisandra Pocojeski ${ }^{\mathrm{II}}$ Leandro Souza da Silva ${ }^{\mathrm{III}}$ Fabio Adriano Graupe ${ }^{\mathrm{IV}}$ \\ Darines Britzke ${ }^{\mathrm{IV}}$
}

\section{RESUMO}

A primeira adubação nitrogenada em cobertura para o arroz irrigado por alagamento pode ser realizada em solo seco ou em lâmina de água, afetando a taxa de volatilização de amônia e, conseqüentemente, a eficiência da adubação nitrogenada. O objetivo deste trabalho foi avaliar as perdas de $N$ por volatilização de amônia com a aplicação de uréia em solo de várzea com diferentes níveis de umidade. $O$ experimento foi conduzido em casa-de-vegetação, utilizandose vasos contendo $5 \mathrm{~kg}$ de um Planossolo Hidromórfico que recebeu os tratamentos: NO - testemunha sem aplicação de uréia (solo úmido); USSE - aplicação de uréia em solo seco; USUM - aplicação de uréia em solo úmido; USSA - aplicação de uréia em solo saturado; e USLA - aplicação de uréia em solo com lâmina de água. As avaliações das perdas de amônia foram realizadas com coletores tipo semi-aberto estático após 10, 24, 34, 48, 72, 96, 144, 192 e 264 horas da aplicação de uréia. Ao final das 264 horas de avaliação, as perdas de amônia foram equivalentes para os tratamentos com aplicação em solo úmido, saturado ou sob lâmina de água, sendo os maiores picos de emissão de amônia entre 34 e 48 horas para o solo úmido e o saturado e 72 horas para a lâmina de água. A aplicação de $N$-uréia sobre a lâmina de água não evitou as perdas de $N$ por volatilização de amônia.

Palavras-chave: manejo do arroz irrigado, $\mathrm{N}-\mathrm{NH}_{3}$, Oryza sativa $L$, adubação nitrogenada.

\section{ABSTRACT}

The first topdressing nitrogen $(N)$ application to flooded rice can be done on dry soil or soil after ponding water, affecting ammonia volatilization rate and, consequently, nitrogen fertilization efficiency. This study was aimed at quantifing $N$ losses by ammonia volatilization after urea application in a wetland soil with different soil water status. The experiment was carried out in a greenhouse, using $5 \mathrm{~kg}$ pots with a Albaqualf with following treatments: NO - control without urea application (wet soil); USSE - urea application on dry soil; USUM - urea application on wet soil; USSA application on saturated soil; and USLA - urea application on soil after ponding water. The ammonia loss evaluations were made using a semi-open static collector at 10, 24, 34, 48, 72, $96,144,192$, and 264 hours after urea application. At the end of 264 hours, the ammonia losses were similar for wet, saturated or ponding water soils, and the higher emission peaks were between 34 and 48 hours in wet and saturated soils and 72 hours in soil after ponding water. The $N$-urea application on ponding water did not avoid the $N$ losses by volatilization.

Key words: flooded rice management, $\mathrm{N}-\mathrm{NH}_{3}$, Oryza sativa $\mathrm{L}$, and nitrogen fertilization.

\section{INTRODUÇÃO}

A produção de arroz no Brasil é originária, principalmente, das lavouras irrigadas por alagamento em área de várzeas do Sul do País, onde o Estado do Rio Grande do Sul (RS) é responsável por aproximadamente metade da produção total e representa mais de dois terços do arroz irrigado colhido (AZAMBUJA et al., 2004). A produtividade média de grãos no Estado do RS está entre as mais altas do Brasil, embora ainda aquém das produtividades obtidas

IFaculdade de Ciências Agrárias, Universidade Nacional de Asunción, Paraguai. E-mail: francis408@hotmail.com.

IIPrograma de Pós-graduação em Ciência do Solo, Centro de Ciências Rurais (CCR), Universidade Federal de Santa Maria (UFSM). Santa Maria, RS, Brasil. E-mail: eliagro@mail.ufsm.br.

IIIDepartamento de Solos, CCR, UFSM, 97105-900, Santa Maria, RS, Brasil. E-mail: leandro@smail.ufsm.br. Autor para correspondência.

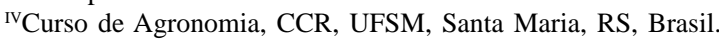


em áreas experimentais e em algumas lavouras mais tecnificadas. Essas diferenças podem ser atribuídas, além de a fatores como solo e clima, às práticas de manejo da lavoura, dentre os quais se destacam os manejos da semeadura, de irrigação, de controle de plantas daninhas, pragas e doenças e da fertilidade do solo.

No manejo da fertilidade do solo, um dos elementos mais influenciados nos sistemas de produção de arroz irrigado é o nitrogênio (N), o qual é requerido pela cultura em grandes quantidades e proporciona maior resposta em termos de produtividade de grãos. Porém, o N apresenta uma dinâmica extremamente complexa no cultivo do arroz, com grande variabilidade nas suas formas químicas em função da umidade do solo (condições aeróbias ou anaeróbias), refletindo diretamente sobre a eficiência do aproveitamento do nutriente pela cultura (FILLERY et al., 1984).

No sistema de produção de arroz irrigado, uma das possíveis perdas do $\mathrm{N}$ aplicado em cobertura com uréia é por meio da volatilização da amônia. $\mathrm{O}$ processo de perda do N por volatilização de amônia consiste na passagem da amônia à atmosfera, conforme a seguinte reação: $\mathrm{N}_{-} \mathrm{NH}_{4}^{+}+\mathrm{OH}^{-}$(aquoso) $\rightarrow \mathrm{H}_{2} \mathrm{O}+\mathrm{N}-$ $\mathrm{NH}_{3}$ (gás). A amônia perdida por volatilização envolve inicialmente a hidrólise da uréia por meio da urease, que é uma enzima extracelular produzida por bactérias, actinomicetos e fungos do solo, ou ainda originada dos restos vegetais (HARGROVE, 1988; BYRNES, 2000), dependendo das condições climáticas e edáficas. Segundo VOLK (1959), o teor de umidade do solo é um fator importante na hidrólise, pois, de maneira geral, pode ocorrer em solos com níveis de umidade variados e, quanto mais rápida a hidrólise, maior o potencial de perda de amônia. Segundo SAVANT et al. (1987), a adição de água promove aumento da difusão da uréia e, conseqüentemente, maior contato com a urease no solo. Outros fatores também afetam a volatilização de amônia, como a temperatura, as trocas gasosas, a taxa de evaporação de água, o poder tampão, a capacidade de troca catiônica e a classe textural (teor de argila) (HARGROVE, 1988; BYRNES, 2000). Outros autores ainda consideram a concentração de $\mathrm{N}$ amoniacal na água de inundação, a velocidade do vento, a quantidades de $\mathrm{N}$ aplicado, o momento vegetativo das plantas quando da aplicação e o método da aplicação deN(VLEK\& CRASWELL, 1981; MIKKELSEN, 1987).

Anteriormente, a recomendação da aplicação de $\mathrm{N}$ em cobertura para o arroz irrigado no sistema de semeadura em solo seco indicava realizar a aplicação após o início da irrigação (CFS-NRS/SBCS, 1995; IRGA, 2001), ou seja, sobre a lâmina de água, de modo a promover a dissolução da uréia e reduzir a volatilização de amônia. Já a nova recomendação de adubação nitrogenada para o arroz irrigado (CQFSNRS/SBCS, 2004; SOSBAI, 2005) indica aplicação de N no início do perfilhamento, preferencialmente, antecedendo a entrada de água na lavoura, de forma que a água de irrigação proceda a sua incorporação ao solo, minimizando as perdas de $\mathrm{N}$ por volatilização de amônia. Neste caso, condiciona-se como intervalo de tempo entre a aplicação do $\mathrm{N}$ e a entrada de água o máximo de três dias para evitar que o $\mathrm{N}$ proveniente da uréia possa ser nitrificado em condições aeróbias e, posteriormente, desnitrificado quando o ambiente tornar-se anaeróbio. Esses fatores de manejo da aplicação de uréia em função do estado de umidade do solo podem representar diferentes possibilidades de perda de $\mathrm{N}$, que podem se refletir na eficiência do fertilizante aplicado e, conseqüentemente, na produtividade da cultura.

O objetivo deste trabalho foi quantificar as perdas de $\mathrm{N}$ por volatilização de amônia, com a aplicação de N-uréia em diferentes teores de umidade de um solo de várzea do RS.

\section{MATERIAL E MÉTODOS}

O experimento foi conduzido na casa-devegetação do Departamento de Solos (DS) da Universidade Federal de Santa Maria (UFSM), município de Santa Maria, localizada na região fisiográfica da Depressão Central do Estado do Rio Grande do Sul. O clima de região enquadra-se na classificação “Cfa” de Köppen, ou seja, clima subtropical úmido sem estiagem, com temperatura média do mês mais quente superior a $22^{\circ} \mathrm{C}$ e a temperatura do mês mais frio entre $-3^{\circ} \mathrm{C}$ e $18^{\circ} \mathrm{C}$ (MORENO, 1961). $\mathrm{O}$ solo foi coletado dos primeiros $20 \mathrm{~cm}$ da área experimental do DS (várzea), destinada para cultura de arroz irrigado, sendo o solo caracterizado como um Planossolo Hidromórfico eutrófico arênico (EMBRAPA, 1999).

O solo de várzea coletado foi peneirado em malha de $2 \mathrm{~mm}$ e secado ao ar, sendo uma porção de $5 \mathrm{~kg}$ transferida para vasos plásticos de $8 \mathrm{~L}$, e estes acondicionados na casa-de-vegetação. Antes de aplicar os tratamentos, foi retirada uma amostra do solo peneirado para realizar a caracterização química no laboratório de análises de solo, obtendo-se os seguintes resultados: teor de argila $=280 \mathrm{~g} \mathrm{~kg}^{-1}$; M.O.= $17 \mathrm{~g} \mathrm{~kg}^{-1} ; \mathrm{pH}_{\mathrm{H} 2 \mathrm{O}}=5,2$; Índice SMP= 6,0; $\mathrm{P}$ (Mehlich-1)= $6,3 \mathrm{mg} \mathrm{L}^{-1}, \mathrm{~K}$ (Mehlich-1) $=48 \mathrm{mg} \mathrm{L}^{-1}, \mathrm{Ca}=7,0 \mathrm{cmol} \mathrm{L}^{-1}$, $\mathrm{Mg}=2,8 \mathrm{cmol} \mathrm{L}^{-1}, \mathrm{Al}=0,9 \mathrm{cmol}_{\mathrm{c}} \mathrm{L}^{-1}$, saturação por $\mathrm{Al}^{\mathrm{c}}{ }^{3+}=$ $8 \%$ e saturação por bases $=74 \%$.

Ciência Rural, v.37, n.3, mai-jun, 2007. 
A aplicação de $\mathrm{N}$ foi equivalente a $100 \mathrm{~kg} \mathrm{ha}^{-1}$, utilizando-se uréia em grânulos como fonte de $\mathrm{N}$, aplicada na superfície do solo. O delineamento experimental utilizado foi completamente casualizado, com quatro repetições, de acordo com os seguintes tratamentos: N0 - testemunha sem aplicação de uréia (solo úmido, considerando $70 \%$ da capacidade de campo); USSE - aplicação de uréia em solo seco; USUM - aplicação de uréia em solo úmido com 70\% capacidade de campo; USSA - aplicação de uréia em solo saturado e USLA - aplicação de uréia em solo com lâmina de água.

As avaliações das perdas de amônia por volatilização para cada tratamento foram realizadas conforme NÔMMIK (1973), com algumas adaptações. Foram utilizadas câmaras coletoras de amônia do tipo semi-aberto estático, construídas a partir de tubo de PVC (cloro-polivinil) de 200mm de diâmetro e 400mm de altura, assentado a um suporte de PVC com $185 \mathrm{~mm}$ de diâmetro e $70 \mathrm{~mm}$ de altura, as quais foram introduzidas no solo dos vasos, em cada tratamento, até uma profundidade de $30 \mathrm{~mm}$ (Figura 1). Sobre os tubos foram colocados suportes de metal aos quais foi acoplada uma tampa plástica protetora, para impedir a entrada de umidade e de raios solares que poderiam afetar o sistema internamente. Em cada câmara coletora foram colocados dois discos de espuma do tipo comercial de $2 \mathrm{~mm}$ de espessura e com densidade 28; o primeiro foi colocado a uma altura de $15 \mathrm{~cm}$ do solo, para capturar a amônia volatilizada do solo, e o segundo a 30cm de altura, para captar a amônia proveniente da atmosfera, impedindo a contaminação do disco inferior. Os discos de espuma foram mantidos sobre uma estrutura metálica adaptada internamente nas câmaras coletoras.
No momento da instalação dos discos de espuma nos coletores de amônia, estes foram embebidos em 100mL de uma solução preparada com $50 \mathrm{~mL}$ de $\mathrm{H}_{3} \mathrm{PO}_{4}$ e $40 \mathrm{~mL}$ de glicerina por litro e, em seguida, foram levemente comprimidos para que ficassem com um volume final de solução de $70 \mathrm{~mL}$, evitando o gotejamento no interior dos cilindros. Os discos inferiores foram trocados a cada intervalo de tempo, enquanto os discos superiores não foram trocados, permanecendo assim até o final do experimento. As avaliações das perdas de amônia foram feitas após 10, 24, 34, 48, 72, 96, 144, 192 e 264 horas da aplicação da uréia no solo. Após cada coleta, o fosfato de amônio formado foi extraído imediatamente dos discos de espuma por meio de oito a dez lavagens sucessivas com solução de $\mathrm{KCl} 1 \mathrm{~mol} \mathrm{~L}^{-1}$. O produto dessa lavagem foi coletado em balões volumétricos, e o volume ajustado para $500 \mathrm{~mL}$ com a solução de $\mathrm{KCl}$, de onde foi retirada uma alíquota de $20 \mathrm{~mL}$ para determinação do equivalente em teor de $\mathrm{N}-\mathrm{NH}_{3}$ em destilador de arraste de vapor semi-micro Kjeldahl, utilizando metodologia descrita por TEDESCO et al. (1995).

Os resultados foram analisados por meio da análise de variância, e as médias dos tratamentos comparadas através do teste de Tukey em nível de 5\% de probabilidade de erro.

\section{RESULTADOS E DISCUSSÃO}

Os maiores picos de emissão de $\mathrm{N}-\mathrm{NH}_{3}$ para a atmosfera ocorreram entre 34 e 48 horas após a aplicação da uréia no solo (Figura 2), tendência observada para os tratamentos com solo úmido (USUM) e saturado (USSA), embora este último tenha retardado o pico em algumas horas em relação ao

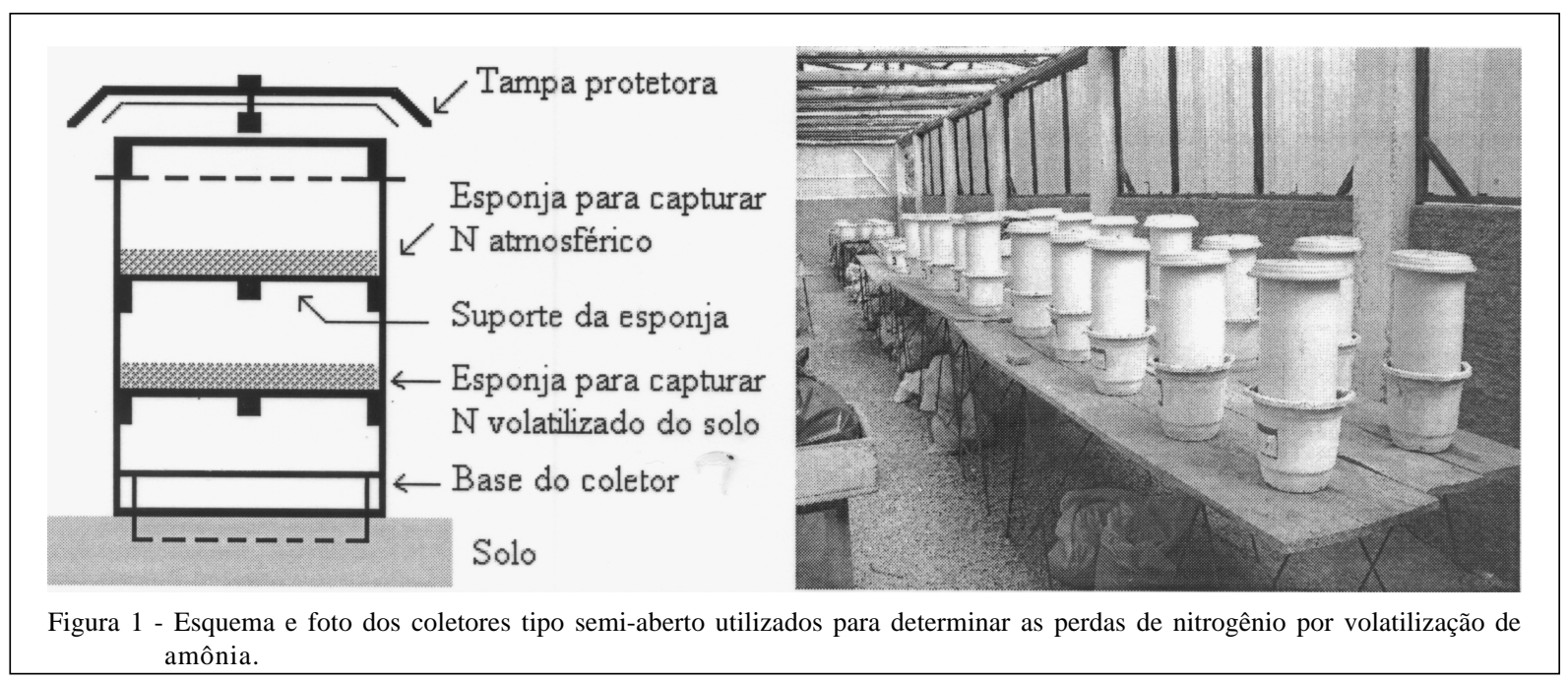

Ciência Rural, v.37, n.3, mai-jun, 2007. 


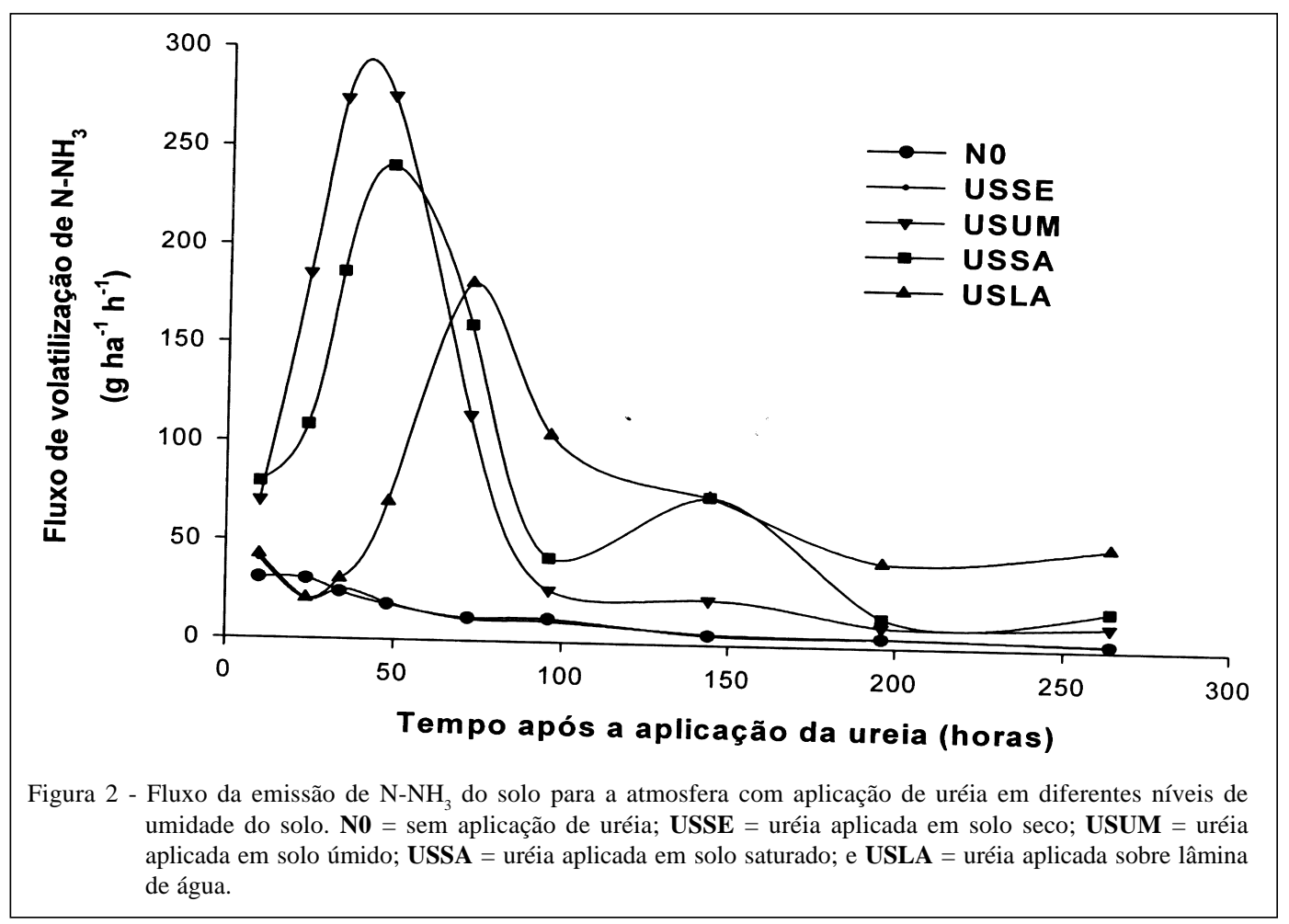

primeiro. Outros estudos já têm verificado que o processo de volatilização de amônia inicia logo após a aplicação da uréia pela rápida hidrólise desta no solo (RODRIGUES \& KIEHL, 1986; SENGIK \& KIEHL, 1995a; LARA-CABEZAS et al., 1997). Entretanto, para o tratamento com lâmina de água (USLA), o pico de emissão de $\mathrm{N}-\mathrm{NH}_{3}$ ocorreu mais tarde, aproximadamente 72 horas após a aplicação. Uma possível explicação para esse comportamento pode estar relacionada com a presença da lâmina de água e a menor difusão de gás nessa condição. Desse modo, a aplicação da uréia sobre a lâmina de água é uma estratégia que não impede a ocorrência da volatilização, e sim retarda seu fluxo para atmosfera.

O tratamento com aplicação de $\mathrm{N}$ em solo seco (USSE) registrou um fluxo semelhante ao tratamento sem aplicação de uréia (N0), o que indica ausência de volatilização de $\mathrm{N}$ durante o período de avaliação com o solo nessas condições. Segundo VOLK (1959), o teor de umidade do solo é um fator importante na hidrólise, pois a adição de água promove aumento da difusão da uréia e, conseqüentemente, maior contato com a urease no solo (SAVANT et al., 1987). De maneira geral, a hidrólise pode ocorrer em solos com níveis de umidade variada e, quanto mais rápida a hidrólise, maior o potencial de perda de amônia. Neste caso, as condições de umidade do solo nesse tratamento não devem ter sido suficientes para que a uréia fosse hidrolisada pela ação da urease, interrompendo a formação dos produtos da reação que proporcionam as perdas de amônia por volatilização. Cabe salientar que, neste tratamento, o solo encontravase em condições de umidade muito baixa, a qual praticamente não seria encontrada em condições de campo, em vista de que causaria prejuízo ao desenvolvimento das plantas.

A maior intensidade de emissão de $\mathrm{N}-\mathrm{NH}_{3}$ foi de aproximadamente $275 \mathrm{~g} \mathrm{ha}^{-1} \mathrm{~h}^{-1}$, para o tratamento USUM, sendo que houve uma redução intensa desta emissão após 96 horas da aplicação, cujos valores ficaram abaixo de $50 \mathrm{~g} \mathrm{ha}^{-1} \mathrm{~h}^{-1}$ (Figura 2). A expressiva redução na taxa diária de volatilização, passadas 96 horas da aplicação da uréia, pode indicar que a amônia moveu-se para camadas mais profundas do solo, onde o processo de volatilização é reduzido (RODRIGUES \& KIEHL, 1986; 1992; HARGROVE, 1988). Essa tendência de diminuição das taxas de emissão de amônia também ocorreu para os tratamentos USSA e USLA, embora um pouco mais tarde do que o tratamento USUM, tendo em vista que a intensidade máxima também ocorreu um pouco mais tarde para esses tratamentos.

Os diferentes fluxos de emissão de $\mathrm{N}-\mathrm{NH}_{3}$ provocados pelos diferentes níveis de umidade do solo resultaram em diferentes quantidades de amônia volatilizada acumulada no período (Tabela 1). As 
Tabela 1 - Perdas acumuladas de $\mathrm{N}-\mathrm{NH}_{3}$ volatilizada $\left(\mathrm{kg} \mathrm{ha}^{-1}\right)$ e percentual de perdas provenientes da aplicação da uréia em diferentes níveis de umidade do solo.

\begin{tabular}{|c|c|c|c|c|c|c|c|c|c|}
\hline \multirow{2}{*}{ Tratamentos } & \multicolumn{9}{|c|}{ Tempo após aplicação da uréia (horas) } \\
\hline & 10 & 24 & 34 & 48 & 72 & 96 & 144 & 192 & 264 \\
\hline & \multicolumn{9}{|c|}{$\mathrm{N}-\mathrm{NH}_{3} \mathrm{~kg} \mathrm{ha}^{-1}$} \\
\hline No & $0,31 b$ & $0,73 b$ & $0,98 b$ & $1,23 b$ & $1,51 \mathrm{c}$ & $1,75 b$ & $2,04 \mathrm{~b}$ & $2,27 b$ & $2,48 b$ \\
\hline USSE & 0,40ab & $0,69 b$ & $0,94 b$ & $1,20 b$ & $1,47 \mathrm{c}$ & $1,73 b$ & $2,03 b$ & $2,23 b$ & $2,46 b$ \\
\hline USUM & 0,70ab & $3,29 a$ & $6,04 \mathrm{a}$ & $9,89 a$ & $12,63 a$ & $13,72 \mathrm{a}$ & $14,36 a$ & $14,87 a$ & $15,74 \mathrm{a}$ \\
\hline USSA & $0,79 a$ & $2,31 b$ & 4,18ab & $7,54 a$ & $11,38 a$ & $12.80 \mathrm{a}$ & $13,82 \mathrm{a}$ & $14,55 a$ & $15,97 \mathrm{a}$ \\
\hline \multirow[t]{2}{*}{ USLA } & $0,42 \mathrm{ab}$ & $0,71 b$ & $1,08 b$ & $2,00 \mathrm{~b}$ & $6,35 b$ & $9,94 a$ & $12,46 a$ & $14,52 \mathrm{a}$ & $18,25 a$ \\
\hline & \multicolumn{9}{|c|}{$\mathrm{N}$ volatilizado em $\%$ do $\mathrm{N}$ aplicado } \\
\hline USSE & $0,09 \mathrm{a}$ & $-0,05 b$ & $-0,04 a b$ & $-0,02 b$ & $-0,04 c$ & $-0,01 b$ & $-0,03 b$ & $-0,04 b$ & $0,03 b$ \\
\hline USUM & $0,39 a$ & $2,55 a$ & $5,06 \mathrm{a}$ & $8,66 a$ & $11,12 \mathrm{a}$ & $11,97 a$ & $12,32 \mathrm{a}$ & $12,60 \mathrm{a}$ & $13,25 \mathrm{a}$ \\
\hline USSA & $0,49 a$ & $1,46 a b$ & 3,19ab & $6,31 \mathrm{a}$ & $8,97 a$ & $11,07 a$ & $11,82 \mathrm{a}$ & $12,32 \mathrm{a}$ & $13,52 \mathrm{a}$ \\
\hline USLA & $0,11 \mathrm{a}$ & $-0,20 b$ & $0,04 \mathrm{ab}$ & $0,76 b$ & $4,83 b$ & $8,19 a$ & $10,42 \mathrm{a}$ & $12,25 a$ & $15,77 a$ \\
\hline
\end{tabular}

N0 = sem aplicação de uréia; USSE = uréia aplicada em solo seco; USUM = uréia aplicada em solo úmido; USSA = uréia aplicada em solo saturado; e USLA = uréia aplicada sobre lâmina de água. N volatilizado em percentagem do $\mathrm{N}$ aplicado= valor do tratamento - valor da

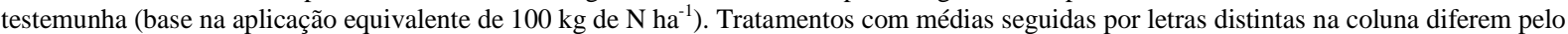
teste de Tukey em nível de 5\% de probabilidade de erro.

maiores perdas acumuladas ocorreram até 144 horas (seis dias) após a aplicação dos tratamentos, exceto para o tratamento USSE que não volatilizou N-NH durante a avaliação, quando comparado com o tratamento N0. Resultados semelhantes foram encontrados por SENGIK \& KIEHL (1995a; 1995b), onde a máxima perda de $\mathrm{N}-\mathrm{NH}_{3}$ por volatilização concentrouse nas primeiras 144 horas após a aplicação do fertilizante. Nas primeiras 24 horas, a maior perda de $\mathrm{N}$ ocorreu para a uréia aplicada no tratamento USUM, enquanto que, entre 24 e 72 horas, as maiores perdas foram para os tratamentos USUM e USSA. A partir das 96 horas da aplicação da uréia, as perdas acumuladas de N por volatilização de amônia para os tratamentos USUM, USSA e USLA foram equivalentes, sendo que praticamente não houve perda de N com a uréia aplicada em USSE (Tabela 1).

A percentagem de $\mathrm{N}$ volatilizado proveniente da uréia, calculada por meio da diferença entre os tratamentos com e sem aplicação de uréia, encontra-se na tabela 1 . As perdas de $\mathrm{N}$ por volatilização após 264 horas (11 dias) da aplicação de uréia variaram entre 13 a $16 \%$ do $\mathrm{N}$ aplicado nos tratamentos USUM, USSA e USLA e ficaram em 0,03\% no tratamento USSE. Estas perdas são da mesma ordem de magnitude das encontradas por SENGIK \& KIEHL (1995a). De maneira geral, as perdas são relativamente baixas, comparadas aos valores normalmente encontrados em condições de sequeiro e a campo por FENN \& KISSEL (1974) e por FERGUSSON et al. (1984), cujas perdas atingiram de 42 a $50 \%$ do $\mathrm{N}$ aplicado na superfície e sem incorporação ao solo (LARA-CABEZAS et al., 1997; 2000). Este fato pode ser parcialmente atribuído ao método empregado na captura da amônia, no qual o dispositivo semi-aberto estático, que permanece isolado da ação do vento durante o período de avaliação, pode subestimar a perda real de $\mathrm{N}$ por volatilização de amônia (THOMPSON et al. 1990; SOMMER \& HUTCHINGS, 2001). Outra variável que determina a intensidade de perda é a temperatura, cuja variação diária e noturna na casa-de-vegetação não foi controlada, estando sujeita às oscilações ambientais ocorridas no período da avaliação. Dessa forma, os valores absolutos de perda devem ser interpretados com cautela e referendados em trabalhos futuros realizados a campo.

Embora as perdas de $\mathrm{N}$ no final do período de avaliação nos solos úmido, saturado e lâmina de água tenham sido equivalentes, a presença das plantas absorvendo parte do $\mathrm{N}$ aplicado, possivelmente, também influenciariam o modo e as condições de aplicação de uréia. Entretanto, a aplicação de uréia para a cultura de arroz irrigado, depois de inundada a cultura (sobre lâmina de água), não se traduz em vantagem para diminuir as perdas por volatilização e aumentar seu aproveitamento. Nesse sentido, considerando a aplicação da uréia antes ao alagamento do solo, as maiores perdas de $\mathrm{N}$ por volatilização vão ocorrer dentro do intervalo de três dias após a aplicação, assim a entrada de água após esse período deverá ter pouco efeito para diminuir as perdas de $\mathrm{N}$ por volatilização. Isso não quer dizer que sua eficiência seja menor que a 
aplicação sobre a lâmina de água, tendo em vista que, nesse tratamento, também ocorreram perdas de $\mathrm{N}$ por volatilização de amônia. A entrada da água de irrigação logo em seguida à aplicação de $\mathrm{N}$ poderia ser uma estratégia para incorporar a uréia ao solo, diminuindo as perdas e aumentando a eficiência da adubação, desde que o $\mathrm{N}$ permanecesse acessível às plantas.

\section{CONCLUSÃO}

A aplicação de N-uréia sobre a lâmina de água proporcionou perda equivalente de $\mathrm{N}$ por volatilização de amônia, acumulada ao final de 264 horas de avaliação, quando comparada com a aplicação em solo úmido ou saturado. A aplicação de N-uréia, para a cultura de arroz irrigado, sobre a lâmina de água, não se traduz em vantagem para diminuir as perdas de $\mathrm{N}$ por volatilização.

\section{AGRADECIMENTOS}

À Fundação de Amparo à Pesquisa do Rio Grande do Sul (FAPERGS), pela concessão da bolsa de iniciação científica e à Coordenação de Aperfeiçoamento de Pessoal de Nível Superior (CAPES), pela concessão de bolsa de mestrado e pelo financiamento parcial da pesquisa.

\section{REFERÊNCIAS}

AZAMBUJA, I.H.V. et al. Aspectos sócio-econômicos da produção do arroz. In: GOMES, A. S.; MAGALHÃES JÚNIOR, A.M. Arroz irrigado no Sul do Brasil. Pelotas: Embrapa Clima Temperado, 2004. p.23-44.

BYRNES, B.H. Liquid fertilizers and nitrogen solutions. In: INTERNATIONAL FERTILIZER DEVELOPMENT CENTER. Fertilizer manual. Alabama: Kluwer Academic, 2000. p.2044.

COMISSÃO DE FERTILIDADE DO SOLO - RS/SC. Recomendações de adubação e calagem para os estados do Rio Grande do Sul e Santa Catarina. 3.ed. Passo Fundo: SBCS - Núcleo Regional Sul/EMBRAPA/CNPT, 1995. 224p.

COMISSÃO DE QUÍMICA E FERTILIDADE DO SOLO - RS/ SC. Manual de adubação e calagem para os Estados do Rio Grande do Sul e Santa Catarina. 10.ed. Porto Alegre: SBCS-Núcleo Regional Sul, 2004. 400p.

EMBRAPA. Centro Nacional de Pesquisa de Solos. Sistema Brasileiro de Classificação de Solos. Brasília: Embrapa Produção de Informação; Rio de Janeiro: Embrapa Solos, 1999. 412p.

FENN, L.B.; KISSEL, D.E. Ammonia volatilization from surface-applications of ammonium compounds on calcareous soils: effects of temperature and rate of ammonium nitrogen application. Soil Science Society of America Proceedings, v.38, p.606-610, 1974.

FERGUSON, R.B. et al. Ammonia volatilization from surfaceapplied urea: effect of hydrogen ion buffering capacity. Soil
Science Society of America Journal, v.48, p.578-582, 1984.

FILLERY, I.R.P. et al. Influence of field environment and fertilizer management on ammonia loss from flooded rice. Soil Science Society of America Journal, v.48, p.914920, 1984.

HARGROVE, W.I. Soil environmental and management factors influencing ammonia volatilization under field conditions. In: BOCK, B.R.; KISSEL, D.E. (Ed). Ammonia volatilization from urea fertilizers. Alabama; NFDC, TVA, 1988. сар.2 p.17-36.

IRGA - INSTITUTO RIO GRANDENSE DO ARROZ. Arroz irrigado: recomendações técnicas para o Sul do Brasil. Porto Alegre, 2001. 128p.

LARA-CABEZAS, W.A.R. et al. Volatilização de NH na cultura de milho: II. Avaliação de fontes sólidas e fluídas em ${ }^{3}$ sistema de plantio direto e convencional. Revista Brasileira de Ciência do Solo, v.21, p.489-496, 1997.

LARA-CABEZAS, W.A.R. et al. Balanço da adubação nitrogenada sólida e fluída de cobertura na cultura de milho, em sistema de plantio direto no triangulo mineiro. Revista Brasileira de Ciência do Solo, v.24, p.363-476, 2000.

MIKKELSEN, D.S. Nitrogen budgets in flooded soils used for rice production. Plant and Soil, v.100, n.1-3, p.71-97, 1987.

MORENO, J.A. Clima do Rio Grande do Sul. Porto Alegre: Secretaria da Agricultura, Divisão de Terras e Colonização, 1961. 42p.

NÔMMIK, $\mathrm{H}$. The effect of pellet size on the ammonia loss from urea applied to forest soil. Plant and Soil, v.39, n.2 p.309-318, 1973.

RODRIGUES, M.B.; KIEHL, J.C. Volatilização de amônia após emprego da uréia em deferentes doses e modo de aplicação. Revista Brasileira de Ciência do Solo, v.10, p.37-43, 1986.

RODRIGUES, M.B.; KIEHL, J.C. Distribuição e nitrificação da amônia proveniente da uréia aplicada ao solo. Revista Brasileira de Ciência do Solo, v.16, p.403-408, 1992.

SAVANT, N.K. et al. Effect of amounts and sequence of additions of urea and water on hydrolysis of surface-applied granular urea in unsaturated soils. Fertilizer Research, v.11, p.231-234, 1987.

SENGIK, E.; KIEHL, J.C. Efeito de resíduos orgânicos e do fosfato monocálcico na volatilização de amônia em terra tratada com uréia. Revista Brasileira de Ciência do Solo, v.19, p.321-326, 1995a.

SENGIK, E.; KIEHL, J.C. Controle da volatilização de amônia em terra tratada com uréia em turfa pelo emprego de sais orgânico. Revista Brasileira de Ciência do Solo, v.19. p.455-461, 1995b.

SOMMER, S.G.; HUTCHINGS, N.J. Ammonia emission from field applied manure and its reduction: invited paper. European Journal of Agronomy, Amsterdam, v.15, n.1, p.1-15, 2001.

Ciência Rural, v.37, n.3, mai-jun, 2007. 
SOSBAI. Sociedade Sul-Brasileira de Arroz Irrigado. Arroz irrigado: recomendações técnicas da pesquisa para o Sul do Brasil. Santa Maria, 2005. 159p.

TEDESCO, J.M. et al. Análise de solos, plantas e outros materiais. Porto Alegre: Departamento de solos, Faculdade de Agronomia. Universidade Federal do Rio Grande do Sul, 1995. 174p.

THOMPSON, R. B. et al. Ammonia volatilization from cattle slurry following surface application to grassland - II: influence of application rate, wind speed and applying slurry in narrow bands. Plant and Soil, v.125, n.1, p.119-128, 1990.

VLEK, P.L.G.; CRASWELL, E.T. Ammonia volatilizations from flooded soils. Fertilizer research, Dordrecht, v.2, p.227245, 1981.

VOLK, M.G. Volatile loss of ammonia following surface application of urea to turf of bare soils. Agronomy Journal. v.51, p.746-749, 1959. 